\title{
Dynamic spare parts transportation model for Arctic production facility
}

\author{
Y. Z. Ayele ${ }^{1}$, A. Barabadi ${ }^{1}$, J. Barabady $^{1 *}$ \\ ${ }^{1}$ UiT The Arctic University of Norway, N-9037 Troms $\varnothing$, Norway
}

\begin{abstract}
Timely delivery of the required spare parts plays an important role in meeting the availability target and reducing the downtime of production facilities. Spare parts logistics is affected in complex ways while operating in the Arctic, since the area is sparsely populated and has insufficient infrastructure. It is also greatly affected by the distinctive operational environment of the region, such as cold temperature, varying forms of sea ice, blizzards, heavy fog, etc. Therefore, in order to have an effective logistic plan, the effect of all influencing factors, called covariates, on the transportation of the spare parts need to be identified, modelled and quantified by the use of an appropriate dynamic model. The traditional models, however, lack the comprehensive integration of the effect of covariates on the spare parts transportation. The purpose of this paper is to introduce the concept of a dynamic model for spare parts transportation in Arctic conditions by considering the time-independent and time-dependent covariates. The model continuously updates the prior probabilities according to the most recent time-dependent covariates to provide posterior probabilities. The application of the model is illustrated using a case study.
\end{abstract}

Keywords: Arctic; production facility; spare parts; time-independent covariate; time-dependent covariate; transportation

\footnotetext{
* Corresponding author: Yonas Zewdu Ayele, Department of Engineering and Safety, UiT The Arctic University
} of Norway, http://www.uit.no, N-9037 Tromsф, Norway; Ph.: +47 77660245, yonas.z.ayele@uit.no 


\section{Introduction}

Spare parts and logistic support have a great impact on the availability of production facilities and on all types of maintenance activities (Hassan et al. 2012). The importance of having spare parts on demand can be more significant for production facilities and systems installed in the environmentally sensitive and remote Arctic region (Ghodrati and Kumar 2005). This is particularly important in the Arctic because of its potentially fragile ecosystem (i.e. potentially irreversible ecological and physical process) (Neff et al. 1987; Schaanning et al. 2008). Therefore, to reduce the health, safety, and environmental (HSE) impact of the industrial activities such as oil and gas industry in the region, the need for high performance production facilities and systems is becoming imperative (Barabadi and Markeset 2011; Barabadi et al. 2014). As a result, production facilities are being designed incorporating non-traditional arrangements and unconventional technologies (Hassan et al. 2012). That means the systems have become more and more specialised or tailor-made. However, with the increased mechanisation and complexity in the production facilities, there is a rise in the number of component failure scenarios (Hassan et al. 2012). Failure of components incurred downtime and unavailability of the system, which can cause substantial production losses and affect business performance (Gao et al. 2010; Barabadi et al. 2014).

To reduce the consequences from component failure and assure effective logistic support, precise estimation of the spare parts transportation time and its associated probability plays a crucial role (Ghodrati et al. 2007; Ayele et al. 2013). It helps to establish a plan that can ensure that the right spare parts and resources are in the right place, at the right time, in the hands of the right person (Ayele et al. 2013). Consequently, it increases the performance and effectiveness of the production facilities. However, the lack of infrastructure, long distance to supply bases and harsh operational conditions in the Arctic make spare parts transportation (delivery) a challenging task.

In the Arctic region, certain storm conditions occur, during which humans cannot venture outside, ice or snow cannot be cleared at the rate at which it is accumulating, ice management cannot operate, ice detection systems do not function to their full capacity, vehicles cannot be operated, etc. (Jacobsen and Gudmestad 2012; Markeset 2008). For those one to three days, no transportation of spare parts can take place. For instance, snow and ice conditions require departing air-cargo planes to undergo de-icing, and if they remain in the take-off line too long they have to return for another treatment, causing lengthy delays and sometimes cancellation. Foggy conditions halt spare parts transportation via helicopter, and sea icing conditions cause a prolonged delay when using ship-cargo. Hence, the Arctic region provides a dynamic operational condition with respect to the transportation time of spare parts.

Over the years, a number of models and approaches have been developed to consider the effect of the dynamic operating environment and estimate the mean transportation time. For instance, Guo and Liu (2011) proposed a day-to-day dynamic model for the application of discrete/continuum representation of transport networks and, consequently, to estimate transportation time. Yerra and Levinson (2005) considered the dynamics of the orientation of major roads in a network and proposed models to understand the basic properties of transport networks during the estimation of transportation time. Li et al. (2012) suggested a model that combines a supply model, which simulates the time-dependent attributes of roads and their 
variations, with a demand model that simultaneously considers heterogeneous users' choices on departure time and route and the effect on transportation time.

However, most of the available models are broad, all-inclusive practical techniques that are developed for off-the-shelf facilities for non-Arctic spare parts transportation operation. To overcome these drawbacks and include the negative adverse effect of the Arctic operational conditions during spare parts transportation, Ayele et al. (2013) proposed the spare parts transportation block diagram approach for estimating the mean spare parts transportation time. However, their approach suffers from limitations as they fail to consider and comprehensively integrate the effect of both time-independent and time-dependent covariates on the spare parts transportation. Further, several models have been studied in the literature to analyse the dynamic behaviour of the transportation network and study the effect of the time-dependent covariates; see e.g. Haghani and Jung (2005), Lo and Szeto (2009), Kaufman and Smith (1993) and Huiskonen (2001). However, the missing point in all of the spare parts logistic literature is to capture and model the time variant operating environment of the Arctic. Given the fastchanging nature of the arduous Arctic environment, this is considered as a big drawback. Further, not fully considering these effects can result in imprecise estimation of transportation time and probabilities (Gao et al. 2010; Barabadi et al. 2012; Kayrbekova et al. 2011). Hence, the model that is used for prediction of the spare parts transportation time must be able to quantify the effect of the dynamic operating environment on transportation time.

The purpose of this paper is thus to introduce a dynamic model for spare parts transportation called Dynamic Spare Parts Transportation Block Diagram (DSTBD), to model the effect of the time-independent and time-dependent covariates on the spare parts transportation operation. The model is based on the consideration of possible transport routes and modes of transport. The first part of the paper describes and introduces the DSTBD model by categorising the operating environment of the Arctic region into two: time-dependent and time-independent covariates. The second part of the paper presents a case study to demonstrate the application of the proposed dynamic model and mathematical formulation. The rest of the paper is organised as follows: Section 2 presents a problem description. Section 3 introduces the DSTBD model. Section 4 presents a description of the case study and the application of the DSTBD model. Section 5 provides the concluding remarks.

\section{Problem description}

The problem considered here is a dynamic spare parts transportation problem with timedependent and time-independent operating environments. Suppose we have a finite number of mode-of-transportation options, each with a different transport time. The idea is to use the most suitable mode of transport and shortest transportation route. However, considering the dynamic effect of the Arctic operational condition on the time to deliver and cost of delivery, a decision maker will face a time-variant decision making process. In other words, the decision maker is faced with an optimisation problem, since the operating environments can be considered as covariates. 
To optimise the spare parts availability and determine what mode of transport will be used, the proposed DSTBD model constantly assesses the operating environment in the general framework of probability models. The proposed model attempts to capture the effect of the dynamic behaviour of the Arctic operating environment on the spare parts transportation. To do this, the model combines operating environment information with actual observed data from weather forecasting: $i$ ) to predict the probability of choosing one transport mode from available choices, ii) to estimate the mean time to delivery of the spare parts, and iii) to predict the probability of having the requested spare parts on-site within the planned delivery time. The approach continuously updates the prior probabilities and deliverability according to the most recent time-dependent covariates to provide posterior probabilities and deliverability.

\section{Dynamic spare parts transportation model}

The dynamic spare parts transportation model/block diagram (DSTBD) is a specialised type of flowchart, which presents the function of dynamic transport network systems, as well as the relationships and interface involved between different modes of transport. The initial idea for the model comes from the dynamic reliability block diagram (DRBD), which is used in reliability engineering to calculate the reliability of the dynamic system (Distefano and Puliafito 2009).

The DSTBD consists of an input/starting point, e.g. manufacturer or supplier warehouse, an output/ending point, e.g. production facility or local inventory, and a set of blocks. Each block represents a transport mode, such as air-cargo, that operates adequately. The block diagram shows how blocks (transport modes) are connected together and is used to help foster understanding of the complete series of transportation models by breaking them down into the three transport modes (air, land and water) (Ayele et al. 2013).

Figure 1 shows an example of a DSTBD with three different possible modes of transport from the starting point and two transport modes from transit to the end point. In Figure $1, P_{i t}$ is the probability of mode $i$ being used from $N$ available alternatives. $D_{i}$ is the spare parts deliverability for a specific transport mode. Spare parts deliverability, for a given network and specific transport mode, is defined as (Ayele et al. 2013): "a probability that the spare parts will be delivered, under a given condition, within a scheduled delivery (transporting) time'. $M T T D_{i}$ is the mean time to delivery, which is a measure of the speed of a given mode of transportation, and dynamic indicator (pointer) [•] is an indicator that can help the user to decide with high probability on the route. In other words, at this point the system will pause and estimate the $P_{i t}$, and consequently the route will be designated based on the high value of $P_{i t}$. 


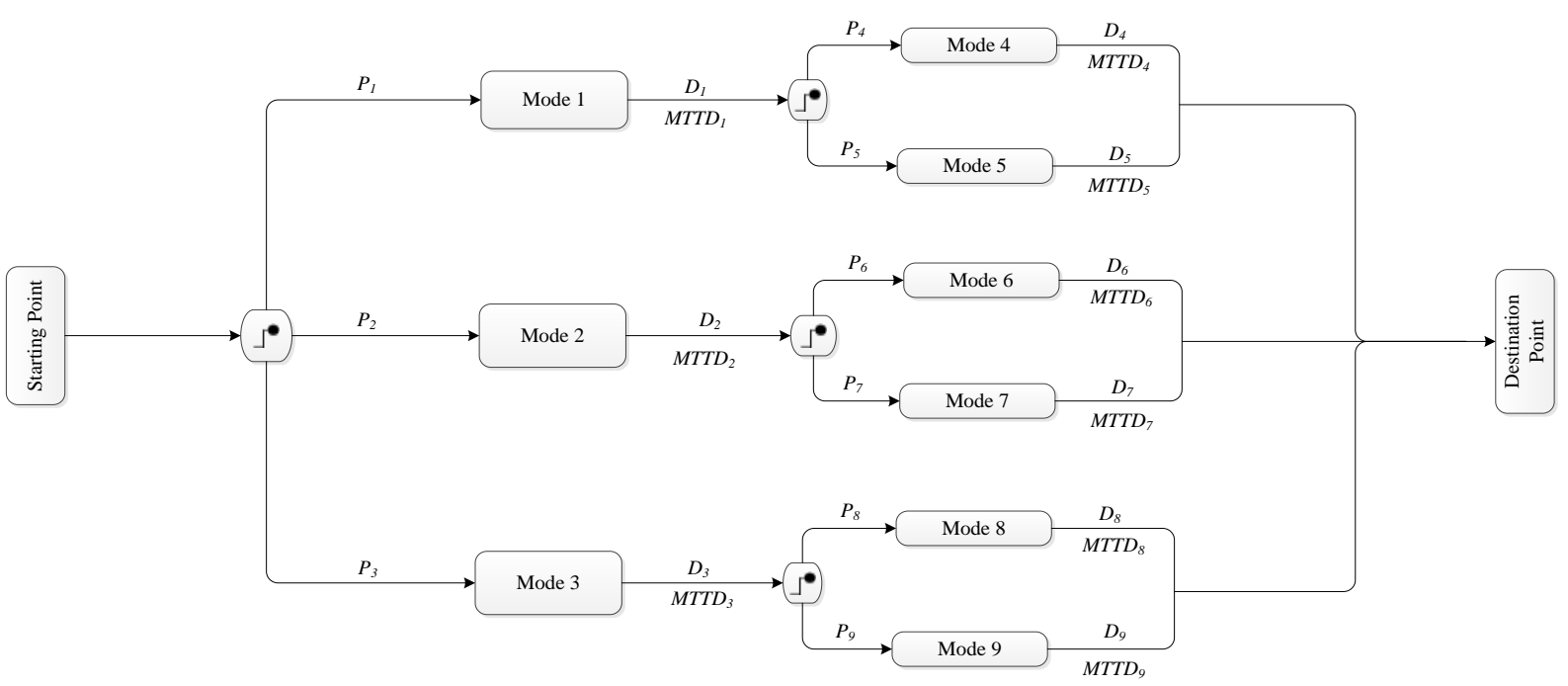

Figure 1. Combined DSTBD

To establish the dynamic spare parts transportation model, firstly all possible time-dependent and time-independent covariates need to be identified. These covariates, in the context of this paper, are factors which arise due to the operating conditions of the Arctic region and can have an influence on the spare parts transportation time. After identification of the covariates, the probabilities of each transport mode, $P_{i t}$, and spare parts deliverability, $D_{i}$, need to be calculated.

\subsection{The probability of mode $i$ being selected from $N$ available alternatives, $P_{i t}$}

The generic probability model, which tends to represent the choice behaviour of the decision maker when provided with a discrete set of transport mode alternatives, is commonly known as the discrete choice model (Khan 2007). There are several modal split models, which are applicable to determine what mode of transport will be used from available alternatives, such as logistic regression, probit model, multinomial logit (Bekhor et al. 2002), multinomial probit, mixed logit (Vovsha 1997), etc. Logit models are one of the most commonly used modal split models, since they possess the ability to model complex network behaviours with simple mathematical techniques (Khan 2007). The mathematical framework of logit models is based on the theory of utility maximisation. The utility is the net benefit that the decision maker $t$ obtains from choosing the mode, $i$; i.e., the decision maker $t$ will choose the alternative that provides the highest utility. Thus, the probability of a decision maker $t$ selecting a transport mode $i$ from $N$ number of available alternatives can be expressed as a multinomial logit (MNL) and is given by Ben-Akiva and Lerman (1985):

$$
P_{i t}=\frac{e^{U_{i t}}}{\sum_{\forall j} e^{U_{j t}}}
$$

where: 
- $P_{i t}$ is the probability of the decision maker $t$ choosing transport mode $i$

- $U_{i t}$ is utility of mode $i$ to decision maker $t$

- $U_{j t}$ is utility of mode $j$ to decision maker $t$

Further, the choice of the decision-maker $t$ can be designated by dummy variables, $y_{i t}$, for each transport mode $i$ :

$$
y_{i t}= \begin{cases}1, & \text { if } U_{i t}>U_{j t} \\ 0, & \text { otherwise }\end{cases}
$$

In general, the probability that a decision-maker $t$ chooses a particular mode of transport $i$ is determined by comparing the utility of choosing that mode (e.g. air-cargo) to the utility of choosing other alternatives (e.g. truck-cargo or ship-cargo). This can be expressed as:

$$
\begin{aligned}
P_{i t} & =\operatorname{Pr}\left(y_{i t}=1\right) \\
& =\operatorname{Pr}\left(U_{i t}>U_{j t} \quad \forall j \neq i\right) \\
& =\operatorname{Pr}\left(U_{i t}-U_{j t}>0 \quad \forall j \neq i\right)
\end{aligned}
$$

To include the dynamic behaviour of the Arctic operating environment and estimate the probabilities of the different mode choices, there are several assumptions embedded in the estimation of MNL models. One such assumption is linear in parameters restriction, which is made for convenience of estimation and enables simple and efficient estimation parameters. For instance, when the functional form of the systematic component of the utility function is linear in parameters, the MNL model proposed by Ben-Akiva and Lerman (1985) can be extended as:

$$
P_{i t}=\frac{e^{\left(\beta_{i} X_{i t}+\delta_{i} X_{i t}\right)}}{\sum_{j=1}^{N} e^{\left(\beta_{j} X_{j t}+\delta_{j} X_{j t}\right)}}
$$

where:

- $X_{i t}$ and $X_{j t}$ are vectors describing the attributes of modes $i$ and $j$.

- $\quad \beta, \delta$ are column vectors consisting of the regression parameters associated with timeindependent and time-dependent covariates, respectively.

In our case, the main attribute of transport modes is the time to delivery (TTD), which is the spare parts transportation time (travel time). As mentioned above, the Arctic region possesses significant variations in operating environment within a short period of time. These variations thus significantly affect the attributes of the specific mode of transport. For instance, the occurrence of blizzards is one of the major causes for the operation of air-cargo and helicopters to be halted in the region. In such cases, the utility from making each of the choices will be dependent on the time-varying covariates. 


\subsection{Spare parts deliverability considering time-dependent and time-independent covariates for a single transport mode $i$}

After estimating the probability, $P_{i t}$, the next step is to estimate the spare parts deliverability. Typically, for each transport mode $i$, the spare parts deliverability can be quantified using a covariate model, such as the proportional hazard model (PHM) (Gao et al. 2010; Cox 1972). To quantify the spare parts deliverability using the PHM, firstly the delivery-rate function should be defined. This function shows how delivery time will be changed (increased or decreased) based on the effect of covariates. Mathematically, delivery-rate function, as a function of baseline delivery-rate and a covariate function, for a given transport mode can be described as follows:

$A_{i}(t, z, z(t))=A_{i o}(t) \psi\left(z, z(t), \beta_{i}, \delta_{i}\right)$

where:

- $A_{i 0}(t)$ is the baseline delivery-rate function, when the effects of all time-dependent and time-independent covariates are summed to zero.

- $\psi\left(z, z(t), \beta_{i}, \delta_{i}\right)$ is a functional term to describe the function of both covariates.

- $z$ and $z(t)$ are time-dependent and time-independent covariates, respectively.

The basic assumption embedded in the estimation of delivery-rate function is that there is a series of $K$ estimated datasets. Each dataset $k$ (ranging from 1 to $K$ ) consists of a set of $K$ times to delivery (TTD), $R$ time-independent covariates and $M$ time-dependent covariates. Table 1 shows a sample of a dataset, which is collected from the major spare parts shipping agents, suppliers, and manufacturers in northern Norway. The covariates were assigned the value zero for absence and one for presence during the spare parts transportation.

Table 1. A sample of a dataset

\begin{tabular}{cccccc}
\hline \hline \multirow{2}{*}{$T T D(\mathrm{hr})$ ) } & \multicolumn{5}{c}{ Time-dependent and time-independent covariates } \\
\cline { 2 - 6 } & Blizzards $(z 1)$ & Fogginess $(z 2)$ & Atmospheric icing $(z 3)$ & Sea spray icing $(z 4)$ & Heavy rain $(z 5)$ \\
\hline \hline 103.00 & 1 & 1 & 0 & 0 & 0 \\
107.00 & 1 & 1 & 1 & 0 & 0 \\
101.00 & 1 & 0 & 1 & 0 & 0 \\
100.00 & 0 & 1 & 1 & 0 & 0 \\
103.00 & 0 & 1 & 0 & 0 & 0 \\
108.00 & 0 & 1 & 0 & 0 & 0 \\
107.00 & 0 & 1 & 0 & 0 & 0 \\
105.00 & 0 & 0 & 1 & 0 & 0 \\
110.00 & 0 & 0 & 0 & 1 & 1 \\
100.00 & 0 & 0 & 0 & 1 & 1 \\
99.00 & 1 & 0 & 1 & 1 & 1 \\
101.00 & 1 & 0 & 1 & 1 & 1 \\
100.00 & 1 & 1 & 1 & 1 & 1 \\
101.00 & 1 & 1 & 0 & 1 & 1 \\
104.00 & 1 & 1 & 0 & 1 & 1 \\
100.00 & 0 & 0 & 1 & & 1 \\
\hline \hline
\end{tabular}


There are various parameterisation forms for expressing the functional term, $\psi\left(z, z(t), \beta_{i}, \delta_{i}\right)$, such as log-linear form, exponential form, etc. If, for instance, the exponential form is considered, the delivery-rate function can be described as follows, by categorising the covariates that satisfy the proportionality assumption and the covariates that do not:

$$
A_{i}(t, z, z(t))=A_{i 0}(t) \exp \left[\sum_{r=0}^{R} \beta_{r, i} z_{r, i}+\sum_{m=0}^{M} \delta_{m, i} z_{m, i}(t)\right]
$$

Then, the spare parts deliverability for a given transport mode can be expressed as:

$$
D_{i}(t, z, z(t))=1-\exp \left[-\int_{0}^{t} A_{i}(\tau, z, z(\tau)) d \tau\right]
$$

By substituting the value of $A_{i}(t, z, z(t))$, the spare parts deliverability can be written as:

$$
D_{i}(t, z, z(t))=1-\exp \left[-\int_{0}^{t}\left[A_{i 0}(\tau) \exp \left[\sum_{r=0}^{R} \beta_{r, i} z_{r, i}+\sum_{m=0}^{M} \delta_{m, i} z_{m, i}(\tau)\right] d_{\tau}\right]\right.
$$

When the covariates are only time-independent $(z(t)=0)$, then Equation (10) can be re-written as:

$$
D_{i}(t, z)=1-\left(1-D_{i 0}(t)\right)^{\exp \left[\sum_{r=0}^{R} \beta_{r, i} z_{r, i}\right]}
$$

where:

- $D_{i 0}(t)$ is the base-line spare parts deliverability for a given transport mode as a function of TTD.

Simply, $D_{i 0}(t)$ is a deliverability value, for 'normal' operating conditions, i.e. when covariates are absent or equal to zero $(z=0$ and $z(t)=0)$. Mathematically, it can be expressed as follows:

$$
D_{i 0}(t)=1-\exp \left[-\int_{0}^{t} A_{i 0}(\tau) d \tau\right]
$$

\subsection{Network spare parts deliverability}

A transportation network is made up of different modes of transport. The main objective of analysing network deliverability is to estimate the overall deliverability of the network, by predicting the deliverability for each transport mode within the intended/planned time. Network spare parts deliverability is calculated by simplifying or breaking the network down into a series 
and parallel network. Then, to calculate the deliverability of the overall network, in the first stage, the deliverability of the spare parts from starting point to the transit, from transit to transits, and from transit to the destination point needs to be estimated.

If considering a series configuration (series transportation network), the spare parts deliverability of the network, $D_{S T N}(t, z, z(t))$, is calculated as:

$$
D_{S T N}(t, z, z(t))=\prod_{i=1}^{N} D_{i}(t, z, z(t))
$$

For a parallel transportation network, $D_{P T N}(t, z, z(t))$ is given as:

$$
D_{P T N}(t, z, z(t))=1-\prod_{i=1}^{N}\left[1-\left(P_{i t} \times D_{i}(t, z, z(t))\right)\right]
$$

\subsection{Mean time to delivery $(M T T D)$}

The mean time to delivery (MTTD), which is a measure of the speed of a given mode of transportation, is calculated as:

$$
\operatorname{MTTD}(t, z, z(t))=\int_{0}^{\infty} t f(t, z, z(t)) d t
$$

where:

- $t$ is the random time to delivery (TTD), for $\forall t \in(0,+\infty)$.

- $f(t, z, z(t))$ is the probability density function of the time to delivery.

\section{An illustrative case study}

The concept of DSTBD will be illustrated for transporting spare parts from the south-western part of Norway to the Johan Castberg Field, Barents Sea, northern Norway. The Johan Castberg Field (formerly Skrugard and Havis) is an oil field development project in the Barents Sea, 200 kilometres from the nearest Ingøya Island, Finnmark, northern Norway. The scenarios of this case study are intended to be used for illustrative purposes only and are hypothetical. The featured scenarios are intended to highlight some of the fundamental usage of the developed concept and its application. The case study emphasised measuring the relative effect of the Arctic operating environment when the decision maker tries to:

- identify suitable transport modes,

- $\quad$ estimate the probability of using one transport mode $i$ from $N$ alternatives,

- predict the spare parts deliverability for each transport mode, and

- estimate the total network spare parts deliverability.

\subsection{Case description}


For the Johan Castberg development project, the operator examines and evaluates various logistic support alternatives. One of the main alternatives is to get the required spare parts support from an onshore operator warehouse located at Veidnes, Finnmark, northern Norway and also from a manufacturer and supplier's warehouse located at Dusavika, Stavanger, in south-western Norway. Figure 2 illustrates the location of the field, the location of the operator and supplier's warehouses as well as the planned transportation routes.

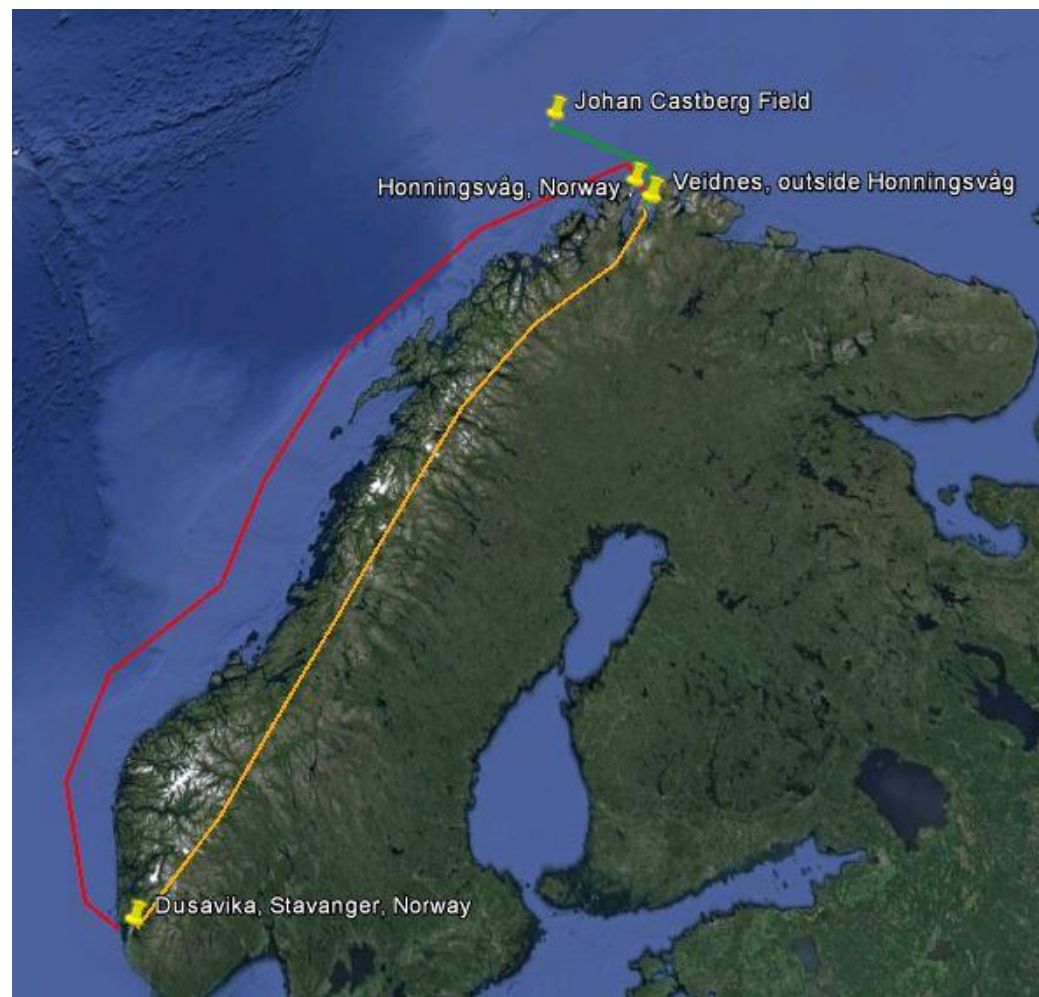

\begin{tabular}{ll}
\hline Colour & Designation \\
\hline & Ship-cargo route from \\
& Dusavika to Veidnes \\
& Truck-cargo route from \\
& Dusavika to Veidnes \\
Ship-cargo route from \\
Veidnes to Johan \\
Castberg Field \\
\hline \hline
\end{tabular}

Figure 2. Illustration of the location of the Johan Castberg field (C) Google Earth

The presumed transport modes are air-cargo, ship-cargo, truck-cargo and helicopter. Figure 3 illustrates the DSTBD for the Johan Castberg development project. Note that the nearest airport from Veidnes is located at Honningsvåg, Finnmark, northern Norway, and once the spare parts are transported using air-cargo to Honningsvåg then they need to be transported to Veidnes using helicopter, ship-cargo or truck-cargo. 


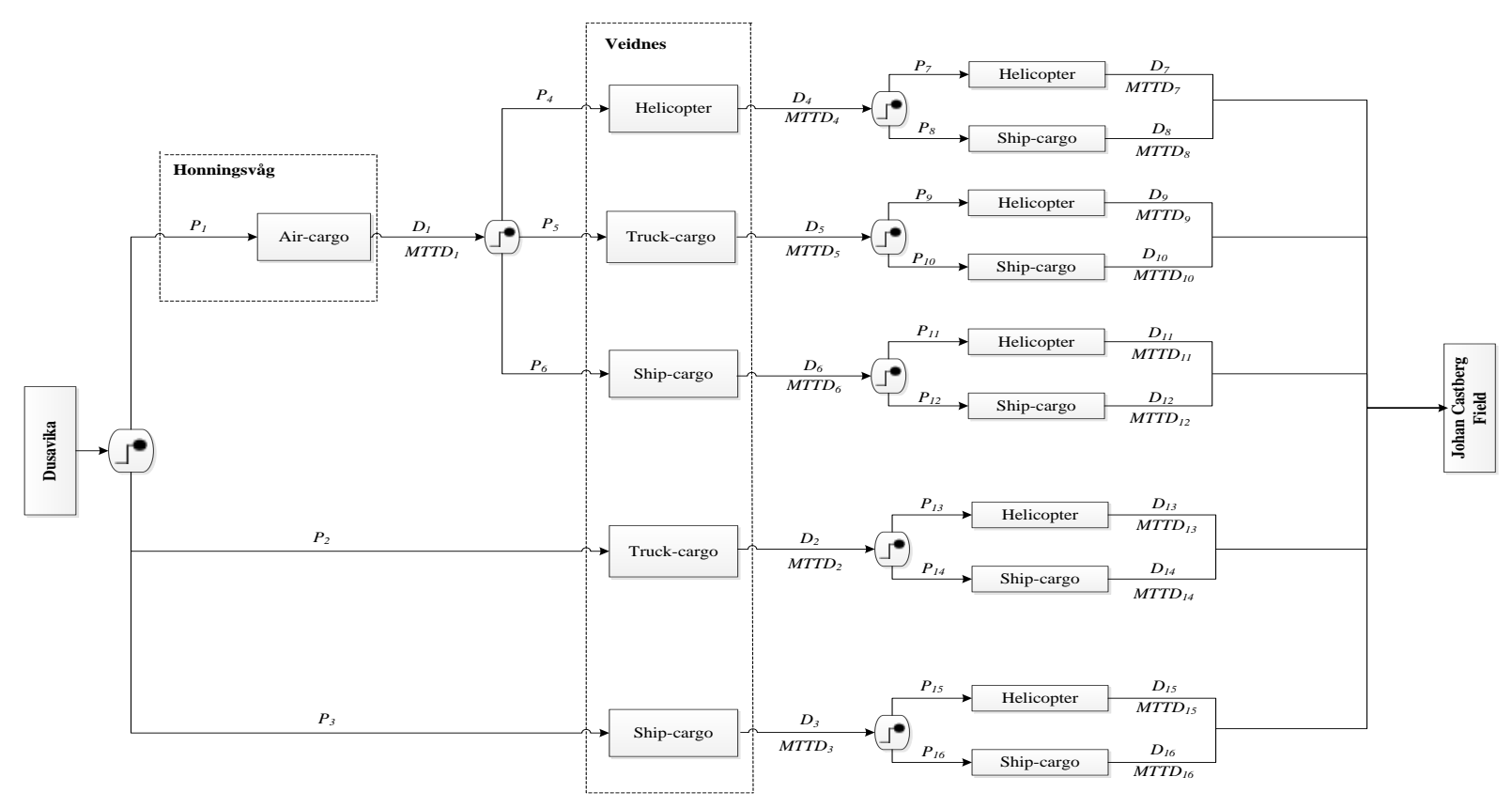

Figure 3. DSTBD for Johan Castberg Field

\subsection{Data collection}

Data on the time to delivery (TTD) for the summer and winter seasons was collected via interviews and meetings with the major shipping agents, suppliers, and manufacturers located in south-western and northern Norway. The TTD data is based on the company's previous and current activities in the region. In addition, Statens vegvesen route planner (a route planner developed by the Norwegian Public Roads Administration) has been used to estimate the transportation time between transits. Table 2 presents a sample of the collected TTD data for different transport modes. Experience shows that there is a difference between TTD during the winter and summer periods; thus, for computational convenience, the calendar time is here considered as a covariate.

Table 2. Sample of $T T D_{A C}, T T D_{T C}, T T D_{S C}$, and $T T D_{H}$

\begin{tabular}{|c|c|c|c|c|c|c|c|c|c|}
\hline \multirow{2}{*}{\multicolumn{2}{|c|}{$\begin{array}{c}\begin{array}{c}\text { Dusavika to } \\
\text { Honningsvåg }\end{array} \\
T T D_{A C}(\text { hr.) }\end{array}$}} & \multicolumn{4}{|c|}{ Dusavika to Veidnes } & \multicolumn{4}{|c|}{ Veidnes to Johan Castberg Field } \\
\hline & & \multicolumn{2}{|c|}{$T T D_{T C}(\mathbf{h r})}$. & \multicolumn{2}{|c|}{$T T D_{S C}(\mathrm{hr})}$. & \multicolumn{2}{|c|}{$T T D_{H}(\mathrm{hr})}$. & \multicolumn{2}{|c|}{$T T D_{S C}(\mathrm{hr})}$. \\
\hline Summer & Winter & Summer & Winter & Summer & Winter & Summer & Winter & Summer & Winter \\
\hline 11.50 & 15.00 & 40.00 & 47.00 & 95.50 & 103.00 & 1.25 & 2.50 & 10.50 & 14.00 \\
\hline 11.50 & 15.00 & 45.00 & 76.00 & 96.00 & 107.00 & 1.25 & 4.00 & 11.00 & 13.00 \\
\hline 12.00 & 14.50 & 43.00 & 56.00 & 96.00 & 101.00 & 1.25 & 2.50 & 10.50 & 15.00 \\
\hline 11.00 & 16.00 & 44.00 & 49.00 & 95.00 & 100.00 & 2.00 & 3.50 & 11.00 & 13.50 \\
\hline 12.00 & 16.00 & 44.00 & 50.00 & 100.00 & 103.00 & 1.25 & 3.50 & 11.00 & 14.00 \\
\hline 14.00 & 16.00 & 48.00 & 53.00 & 95.00 & 108.00 & 1.25 & 3.00 & 10.50 & 15.00 \\
\hline 13.00 & 18.50 & 43.00 & 71.00 & 96.00 & 107.00 & 3.00 & 5.00 & 12.00 & 11.50 \\
\hline 12.00 & 17.00 & 45.00 & 66.00 & 97.00 & 105.00 & 3.00 & 4.50 & 11.00 & 12.00 \\
\hline 13.50 & 17.00 & 44.00 & 54.00 & 96.00 & 110.00 & 1.50 & 3.00 & 10.00 & 13.00 \\
\hline 11.00 & 16.00 & 46.00 & 58.00 & 96.00 & 100.00 & 2.50 & 3.00 & 11.50 & 12.00 \\
\hline
\end{tabular}




\begin{tabular}{llllllllll}
12.00 & 17.00 & 45.00 & 50.00 & 96.00 & 99.00 & 4.00 & 6.00 & 12.00 & 15.00 \\
14.00 & 18.00 & 41.00 & 64.00 & 98.00 & 100.00 & 2.50 & 2.50 & 10.50 & 14.00 \\
13.50 & 19.00 & 43.00 & 50.00 & 97.00 & 100.00 & 1.50 & 2.50 & 10.50 & 16.00 \\
12.00 & 16.00 & 40.00 & 59.00 & 95.50 & 101.00 & 2.00 & 3.00 & 11.00 & 13.00 \\
13.00 & 15.00 & 50.00 & 61.00 & 95.00 & 104.00 & 1.25 & 3.00 & 10.50 & 12.50 \\
14.00 & 15.00 & 45.00 & 46.00 & 97.00 & 100.00 & 2.00 & 3.00 & 11.00 & 13.00 \\
\hline \hline
\end{tabular}

- $T T D_{A C}$ is the $T T D$ of an air-cargo; $T T D_{T C}$ is the TTD of a truck-cargo; $T T D_{S C}$ is the TTD of a ship-cargo; and $T T D_{H}$ is the $T T D$ of a helicopter. The distance from Dusavika to Veidnes equals approximately $2535.0 \mathrm{KM}$ using truck-cargo and 1050.0 NM (1945 KM) using ship-cargo. From Veidnes to Johan Castberg Field, the distance is approximately 113 NM (209 KM) using ship-cargo.

\subsection{Data analysis}

The analysis of the data is based on the following assumptions: $i$ ) the weight and size of the spare parts are within an acceptable range. Hence, the presumed modes can be used to transport the spare parts, and $i i)$ the total scheduled delivery time $\left[T_{S D T}\right]$ for transporting the spare parts from Dusavika to Veidnes via Honningsvåg and then to the Johan Castberg Field equals 110 hours. The total scheduled time can be broken down into two parts: i) from Dusavika to Veidnes, which is 95 hours, and ii) from Veidnes to Johan Castberg Field, which is 15 hours. Figure 4 illustrates the scheduled delivery times. As part of scheduled delivery time $1\left[T_{S D T_{1}}\right]$, scheduled delivery time $3\left[T_{S D T_{3}}\right]$ equals 10 hours for transporting the spare parts from Honningsvåg to Veidnes.

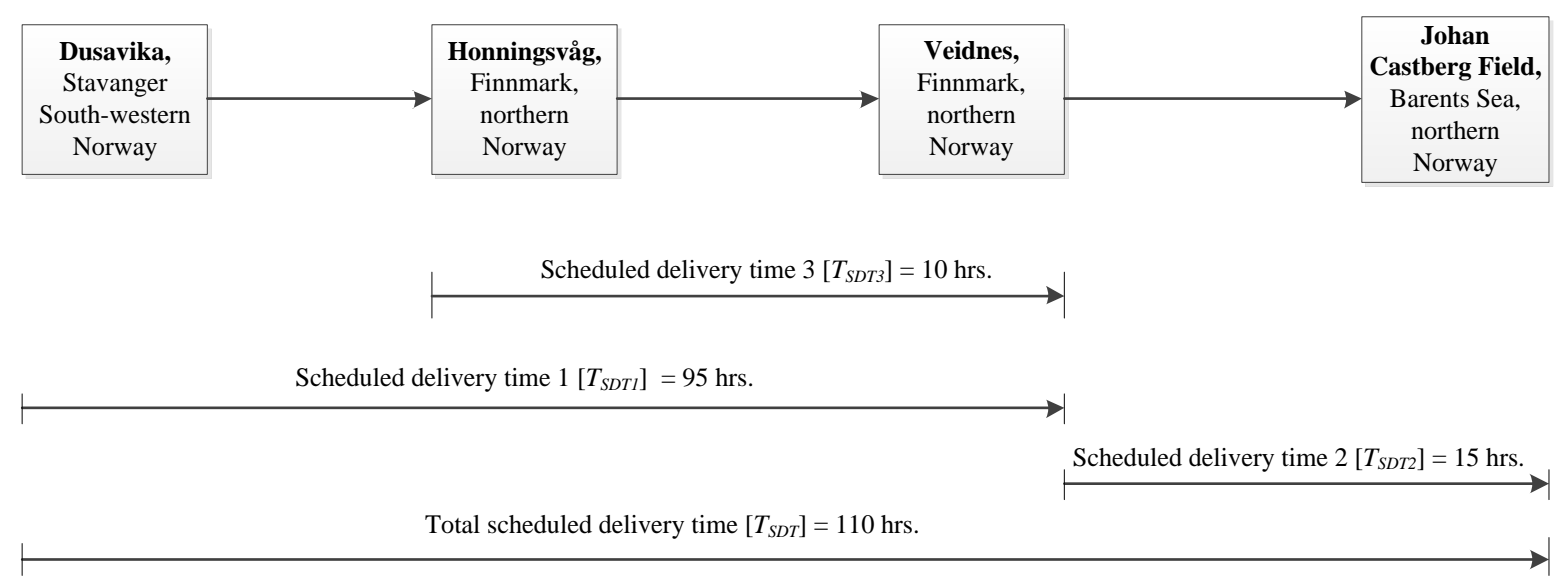

Figure 4. Illustration of the scheduled delivery times

\subsubsection{Estimating the mean time to delivery $(M T T D)$ for the defined transport modes}

To estimate the MTTD for each transport mode, different distribution functions, such as normal, log-normal or Weibull, were nominated. Thereafter, the best-fit distributions for the data were identified. In this paper, Weibull ++7 distribution wizard is used as a tool to estimate the bestfit distribution for the given data (ReliaSoft 2007). Figure 5 shows the probability density function $(p d f)$ of TTD for ship-cargo from Dusavika to Veidnes for the summer season. 


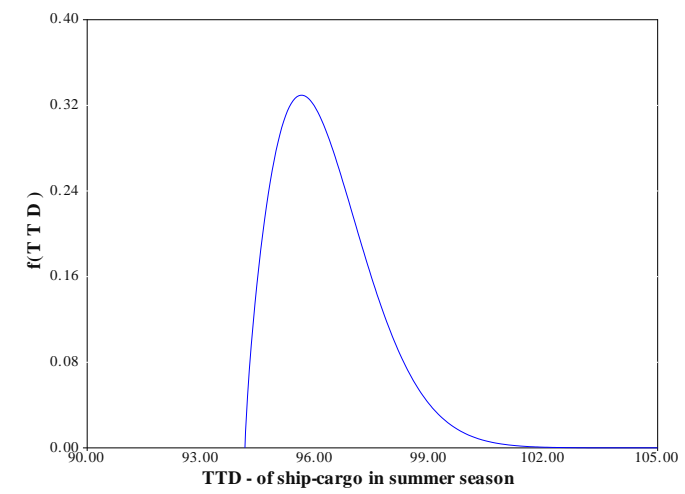

Figure 5. Probability density function ( $p d f)$ of $T T D$ of ship-cargo

Afterwards, the distribution parameters were calculated using available methods such as maximum likelihood (MLE) methods, and then the MTTD were estimated. The results from the $T T D$ data analysis for different transportation modes are summarised in Table 3.

Table 3. Estimated MTTD

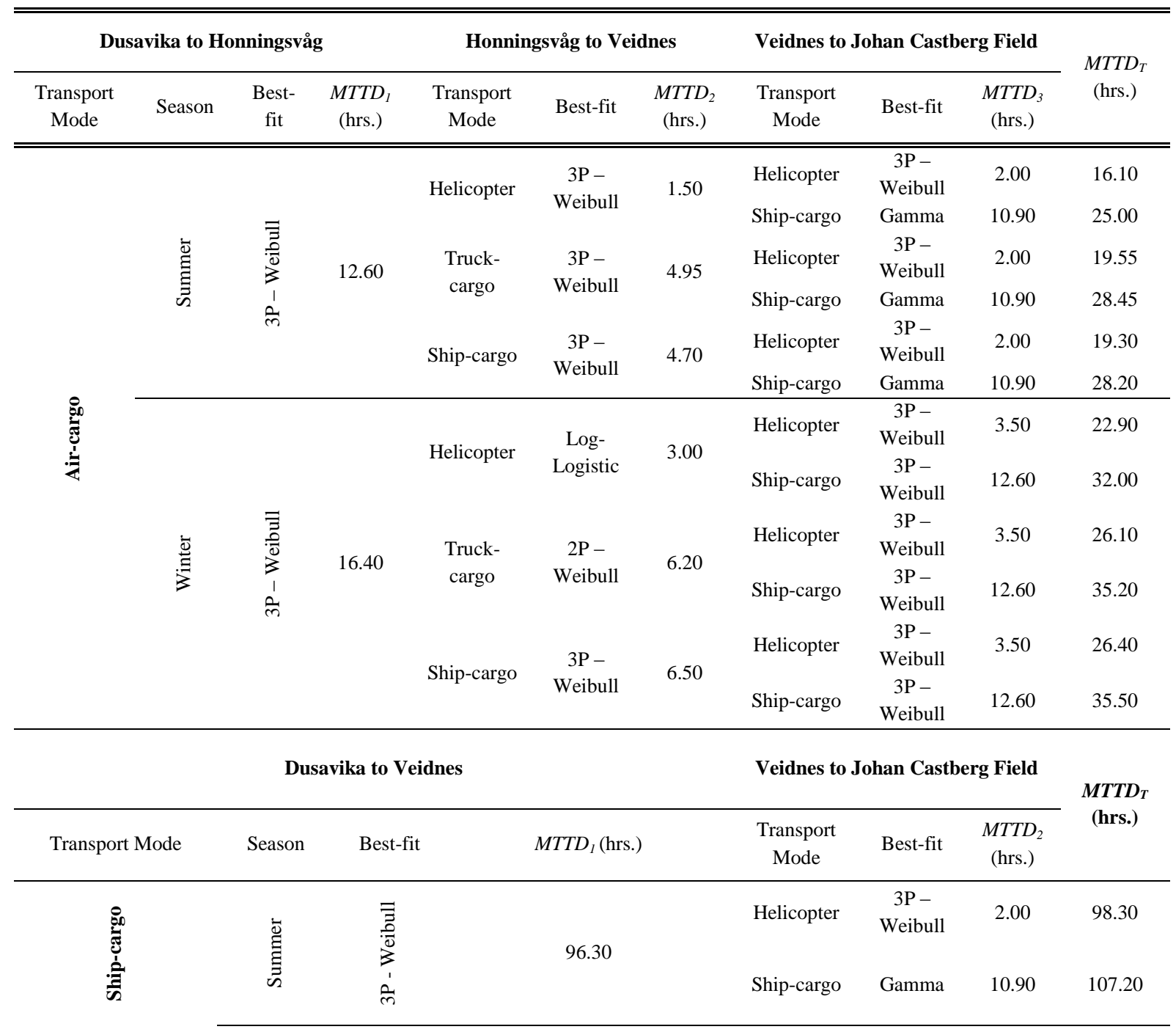




\begin{tabular}{|c|c|c|c|c|c|c|c|}
\hline & \multirow{2}{*}{ 离 } & \multirow{2}{*}{$\begin{array}{l}\bar{\Xi} \\
\frac{0}{0} \\
3 \\
1 \\
\text { 'े }\end{array}$} & \multirow[b]{2}{*}{103.20} & Helicopter & $\begin{array}{c}3 \mathrm{P}- \\
\text { Weibull }\end{array}$ & 3.50 & 106.70 \\
\hline & & & & Ship-cargo & $\begin{array}{c}3 \mathrm{P}- \\
\text { Weibull }\end{array}$ & 12.60 & 115.80 \\
\hline \multirow{4}{*}{ 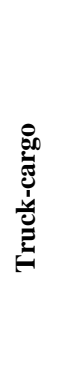 } & \multirow{2}{*}{ 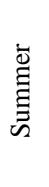 } & \multirow{2}{*}{ 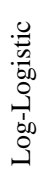 } & \multirow{2}{*}{44.10} & Helicopter & $\begin{array}{c}3 \mathrm{P}- \\
\text { Weibull }\end{array}$ & 2.00 & 46.10 \\
\hline & & & & Ship-cargo & Gamma & 10.90 & 55.00 \\
\hline & \multirow{2}{*}{ 离 } & $\begin{array}{l}\bar{B} \\
\overline{0} \\
2\end{array}$ & \multirow{2}{*}{57.40} & Helicopter & $\begin{array}{c}3 \mathrm{P}- \\
\text { Weibull }\end{array}$ & 3.50 & 60.90 \\
\hline & & $\dot{m}$ & & Ship-cargo & $\begin{array}{c}3 \mathrm{P}- \\
\text { Weibull }\end{array}$ & 12.60 & 70.00 \\
\hline
\end{tabular}

- $\quad M T T D_{T}$ is the total mean time to delivery from Dusavika to Johan Castberg Field via Veidnes and it is a summation of $M T T D_{1}, M T T D_{2}$, and $M T T D_{3}$.

The MTTD analysis result illustrates that the operational conditions of the Arctic have a significant effect on the spare parts transportation time during the winter season. Figure 6 shows the comparison between $M T T D$ of different transport modes during the summer and winter seasons, when transporting the spare parts from Dusavika to Honningsvåg then to the Johan Castberg Field via Veidnes.

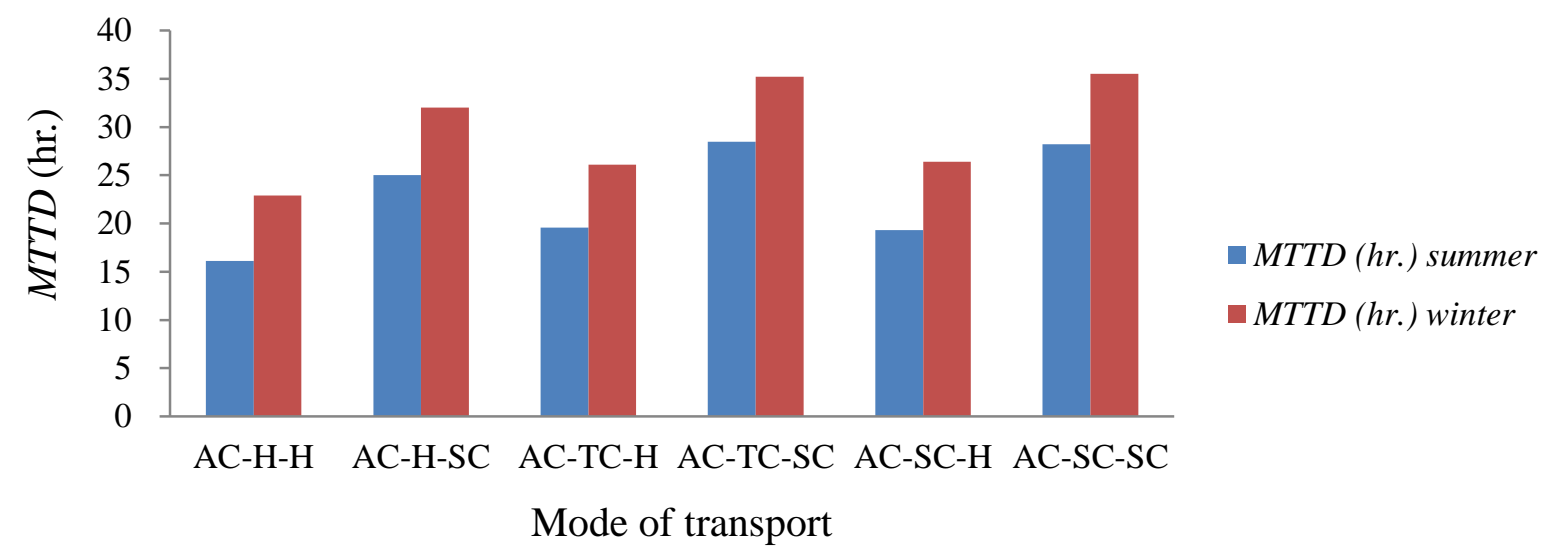

Figure 6. MTTD (hr.) summer vs. MTTD (hr.) winter. AC : Air-cargo; H: Helicopter; SC: Ship-cargo; TC: Truck-cargo. For instance, AC-H-H represents the use of Air-cargo from Dusavika to Honningsvåg, Helicopter from Honningsvåg to Veidnes, and Helicopter from Veidnes to the Johan Castberg Field.

To compare the percentage change between the MTTD during the summer and winter season, the following formulation has been used:

$$
\text { Pecentage }(\%)=\left(\frac{M T T D_{\text {WINTER }}-M T T D_{\text {SUMMER }}}{M T T D_{\text {SUMMER }}}\right) \times 100
$$

Then, by employing Equation (16) and comparing the MTTD of the air-cargo of the summer and winter seasons, there is approximately $30 \%$ extended delay during the winter season, when transporting the spare parts from Dusavika to Honningsvåg. This percentage increases to a $100 \%$ when transporting the spare parts from Honningsvåg to Veidnes, using helicopter as a 
transport mode. Table 4 summarises the comparison results of the MTTD between the summer and winter seasons, for the air-cargo, helicopter, truck-cargo and ship-cargo.

Table 4. Increased percentage change during the winter season

\begin{tabular}{|c|c|c|c|c|c|}
\hline \multicolumn{2}{|c|}{ Dusavika to Honningsvåg } & \multicolumn{2}{|c|}{ Honningsvåg to Veidnes } & \multicolumn{2}{|c|}{$\begin{array}{c}\text { Veidnes to Johan Castberg } \\
\text { Field }\end{array}$} \\
\hline $\begin{array}{l}\text { Transport } \\
\text { Mode }\end{array}$ & $\begin{array}{c}\text { Increased } \\
\text { Percentage } \\
\text { change }(\%)\end{array}$ & $\begin{array}{l}\text { Transport } \\
\text { Mode }\end{array}$ & $\begin{array}{c}\text { Increased } \\
\text { Percentage } \\
\text { change }(\%)\end{array}$ & $\begin{array}{l}\text { Transport } \\
\text { Mode }\end{array}$ & $\begin{array}{c}\text { Increased } \\
\text { Percentage } \\
\text { change }(\%)\end{array}$ \\
\hline Air-cargo & 30.16 & $\begin{array}{c}\text { Helicopter } \\
\text { Truck-cargo } \\
\text { Ship-cargo }\end{array}$ & $\begin{array}{l}100.00 \\
25.25 \\
38.30\end{array}$ & Helicopter & 75.00 \\
\hline \multicolumn{4}{|c|}{ Dusavika to Veidnes } & \multirow{3}{*}{ Ship-cargo } & \multirow{3}{*}{15.60} \\
\hline $\begin{array}{r}\text { Trai } \\
\mathrm{S}\end{array}$ & $\begin{array}{l}\text { Mode } \\
\operatorname{argo}\end{array}$ & \multicolumn{2}{|c|}{7.17} & & \\
\hline & argo & \multicolumn{2}{|c|}{30.16} & & \\
\hline
\end{tabular}

- Note that when air-cargo is utilized as our transport mode, then to get to Veidnes we have to use the nearest airport terminal, which is Honningsvåg airport. Then, the spare parts have to be transported to the Johan Castberg Field via Veidnes.

\subsubsection{Estimating the probability of using mode $i, P_{i t}$}

To estimate the probabilities of using transport mode $i, P_{i t}$, the best-fit distribution results from Weibull ++7 distribution wizard have been used. The probabilities are classified for both summer and winter seasons. Table 5 shows the best-fit distribution for the TTD data and the distribution parameters for the summer season, when transporting the spare parts from Dusavika to Veidnes.

Table 5. Best-fit distribution and estimated parameters [for summer season]

\begin{tabular}{cccc}
\hline \hline & Dusavika to Honningsvåg to Veidnes & \\
\hline Transport Mode & Best-fit distribution & \multicolumn{2}{c}{ Parameters } \\
\hline \hline \multirow{2}{*}{ Air-cargo } & & $\beta$ & 1.42 \\
& 3P-Weibull & $\eta(\mathrm{hr})$. & 2.07 \\
Truck-cargo & & $\gamma(\mathrm{hr})$. & 10.71 \\
& Log-Logistic & $\mu(\mathrm{hr})$. & 3.79 \\
Ship-cargo & & $\sigma$ & 0.04 \\
& 3P-Weibull & $\beta$ & 2.00 \\
\hline \hline
\end{tabular}

The result from the analysis shows that for air-cargo and ship-cargo the best-fit distribution is $3 \mathrm{P}$ - Weibull, and for truck-cargo, it is Log-logistic. Then, for instance, to estimate the probability of using air-cargo $\left(P_{A C}\right)$ over ship-cargo and truck-cargo (i.e. preferring air-cargo), Equation (6) can be re-written as follows: 


$$
P_{A C}=\frac{\left(1-\exp ^{-}\left(\frac{t-\gamma}{\eta}\right)^{\beta}\right)}{1+\left[\left(\frac{\exp \left(\frac{(\ln (t)-\mu}{\sigma}\right)}{1+\exp \left(\frac{(\ln (t)-\mu}{\sigma}\right)}\right)+\left(1-\exp ^{-}\left(\frac{t-\gamma}{\eta}\right)^{\beta}\right)\right]}
$$

The probabilities are calculated, for each mode of transport, by substituting the parameters from Table 5 and based on the assumed scheduled delivery times. The results are presented in Table 6 for both the summer and winter seasons. An example of a detailed estimation of the probabilities can be referred to in the Appendix.

Table 6. Estimated $P_{i t}$

\begin{tabular}{|c|c|c|c|c|}
\hline \multirow{3}{*}{ Season } & \multicolumn{2}{|c|}{ Dusavika to Honningsvåg to Veidnes } & \multirow{2}{*}{\multicolumn{2}{|c|}{$\begin{array}{l}\text { Veidnes to Johan Castberg Field } \\
\qquad T_{S D T_{2}}=15 \mathrm{hr} .\end{array}$}} \\
\hline & \multicolumn{2}{|c|}{$T_{S D T_{1}}=95 \mathrm{hr}$} & & \\
\hline & Mode of Transport & $P_{i t}$ & Mode of Transport & $P_{i t}$ \\
\hline \multirow{4}{*}{ Summer } & Air-cargo & 0.48 & \multirow{4}{*}{$\begin{array}{l}\text { Helicopter } \\
\text { Ship-cargo }\end{array}$} & \multirow{4}{*}{$\begin{array}{l}0.60 \\
0.40\end{array}$} \\
\hline & & & & \\
\hline & Truck-cargo & 0.48 & & \\
\hline & Ship-cargo & 0.04 & & \\
\hline \multirow{4}{*}{ Winter } & Air-cargo & 0.49 & \multirow{4}{*}{$\begin{array}{l}\text { Helicopter } \\
\text { Ship-cargo }\end{array}$} & \multirow{4}{*}{$\begin{array}{l}0.40 \\
0.60\end{array}$} \\
\hline & Truck-caroo & 030 & & \\
\hline & 1тuck-cargo & 0.50 & & \\
\hline & Ship-cargo & 0.21 & & \\
\hline \multirow{2}{*}{ Season } & \multicolumn{4}{|c|}{ Honningsvåg to Veidnes, $T_{S D T_{3}}=10 \mathrm{hr}$. } \\
\hline & \multicolumn{2}{|c|}{ Mode of Transport } & \multicolumn{2}{|r|}{$P_{i t}$} \\
\hline \multirow{3}{*}{ Summer } & \multicolumn{2}{|c|}{ Helicopter } & \multicolumn{2}{|r|}{0.34} \\
\hline & \multicolumn{2}{|c|}{ Truck-cargo } & \multicolumn{2}{|r|}{0.34} \\
\hline & \multicolumn{2}{|c|}{ Ship-cargo } & \multicolumn{2}{|r|}{0.32} \\
\hline \multirow{3}{*}{ Winter } & \multicolumn{2}{|c|}{ Helicopter } & \multicolumn{2}{|r|}{0.33} \\
\hline & \multirow{2}{*}{\multicolumn{2}{|c|}{$\begin{array}{l}\text { I ruck-cargo } \\
\text { Ship-cargo }\end{array}$}} & \multicolumn{2}{|r|}{0.34} \\
\hline & & & \multicolumn{2}{|r|}{0.33} \\
\hline
\end{tabular}

\subsubsection{Estimating the spare parts deliverability for a given transport mode}

To estimate the spare parts deliverability for each transport mode, the modified DSTBD formulations have been used. Regression parameters are estimated using IBM SPSS software, in the first stage. In the next stage, the significance of each regression coefficient $\beta_{i}$ was tested by calculating the Wald statistics and its p-value. Table 7 presents the results from the 
regression analysis. To check the significance of the covariates, in this case study, the upper limit of the p-value is considered as $5 \%$, which is based on the suggestion by Barabadi et al. (2011). In Table 7, $\operatorname{Exp}\left(\beta_{i}\right)$ is the delivery-rate ratio, and it predicts the change in the deliveryrate for each transport mode during different seasons. If $\operatorname{Exp}\left(\beta_{i}\right)$ is less than 1.0, then the direction of the effect is towards reducing the delivery-rate. If the value 1 appears within the confidence interval of covariates, the effect of that covariate is considered to be insignificant.

Table 7. Covariates and their significance with the modified deliverability model

\begin{tabular}{cccccccccc}
\hline \hline Transport Mode & Covariate & \multirow{2}{*}{$\beta_{i}$} & SE & \multirow{2}{*}{ Wald } & df & \multirow{2}{*}{ Sig. } & \multirow{2}{*}{$\operatorname{Exp}\left(\beta_{i}\right)$} & \multicolumn{2}{c}{$95.0 \% \mathrm{CI}$ for $\operatorname{Exp}\left(\beta_{i}\right)$} \\
\cline { 7 - 10 } & & & & & & & & Lower & Upper \\
\hline Air-cargo & Season & -1.376 & .420 & 10.763 & 1 & .001 & .253 & .111 & .575 \\
Truck-cargo 1* & Season & -2.344 & .525 & 19.957 & 1 & .000 & .096 & .034 & .268 \\
Ship-cargo 1* & Season & -1.163 & .417 & 7.789 & 1 & .005 & .312 & .138 & .707 \\
Helicopter 2*** & Season & -1.652 & .424 & 15.198 & 1 & .000 & .192 & .084 & .440 \\
Truck-cargo 2** & Season & -1.405 & .484 & 8.425 & 1 & .004 & .245 & .095 & .634 \\
Ship-cargo 2** & Season & -1.562 & .446 & 12.266 & 1 & .000 & .210 & .088 & .503 \\
Helicopter 3*** & Season & -1.181 & .388 & 9.289 & 1 & .002 & .307 & .144 & .656 \\
Ship-cargo 3*** & Season & -1.524 & .459 & 11.042 & 1 & .001 & .218 & .089 & .535 \\
\hline \hline
\end{tabular}

- where $1 *$ is the transport mode from Dusavika to Veidnes, $2 * *$ from Honningsvåg to Veidnes, and $3 * * *$ from Veidnes to Johan Castberg Field.

Then, by employing the results from the regression analysis and substituting the values into Equation (8), the delivery-rate function for air-cargo, $A_{A C}(t, z, z(t))$, for the winter season can be written as follows:

$$
A_{A C}(t, z, z(t))=A_{A C 0}(t) \exp [-1.376]=0.253 A_{A C 0}(t)
$$

where:

- $A_{A C 0}(t)$ is the delivery-rate function for air-cargo during the summer season.

Afterwards, by substituting the value of $A_{A C}(t, z, z(t))$ into Equation (10), the spare parts deliverability for air-cargo during the winter season can be written as:

$$
D_{A C}(t, z, z(t))=1-\left[\left(1-D_{A C 0}(t)\right)^{0.253}\right]
$$

where:

- $\left.D_{A C 0}(t)\right)$ is the base-line spare parts deliverability of the air-cargo during the summer season.

\subsubsection{Estimating the network spare parts deliverability}

By applying the same approach, the network spare parts deliverability for different transportation modes and routes of transportation is estimated and summarised in Table 8. 
Table 8. Network spare parts deliverability in summer and winter seasons



- $D_{N 1}(t, z, z(t))$ - is the network spare parts deliverability from Dusavika to Honningsvåg; $D_{N 2}(t, z, z(t))-$ from Honningsvåg to Veidnes; $D_{N 3}(t, z, z(t))$ - from Veidnes to Johan Castberg Field. $D_{N E T}(t, z, z(t))$ is the total network deliverability, which is given as $D_{N E T}(t, z, z(t))=D_{N 1}(t, z, z(t)) \times D_{N 2}(t, z, z(t)) \times D_{N 3}(t, z, z(t))$.

The result of the spare parts deliverability analysis shows that:

- For the summer season, the most suitable way of transporting the spare parts from Dusavika to Veidnes is using truck-cargo $\left(P_{T C}=0.48\right)$ and from Veidnes to the Johan Castberg Field is by either ship-cargo or helicopter $\left(P_{S C}=P_{H}=0.60\right)$.

- For the winter season, using truck-cargo $\left(P_{T C}=0.30\right)$ from Dusavika to Veidnes and shipcargo $\left(P_{S C}=0.57\right)$ from Veidnes to the Johan Castberg Field is most suitable.

To compare the results of the most suitable transport modes (i.e. modes with high $P_{i t}$ and $D_{i}$ ) for spare parts deliverability during the summer and winter seasons, the following formulation has been used: 
Percentage change $(\%)=\left(\frac{D_{i}(t, z, z(t))_{\text {SUMMER }}-D_{i}(t, z, z(t))_{\text {WINTER }}}{D_{i}(t, z, z(t))_{\text {WINTER }}}\right) \times 100$

Then, by inserting the estimated results, the percentage change is calculated as follows:

Percentage $(\%)=\left(\frac{0.288-0.171}{0.171}\right) \times 100=68.42$

The result illustrates that there is approximately $68 \%$ delay during the winter season due to the Arctic operational conditions, when transporting the spare parts from Dusavika to the Johan Castberg Field via Veidnes. Further, the result is significantly dependent on the data, which need to be updated according to the most recent time-dependent covariates.

\section{Conclusion}

To meet the availability goals of production facilities, the requested spare parts need to be available upon demand. This has a significant economic impact in helping to maintain the availability of the production systems, reducing the downtime and facilitating the maintenance process. However, the demanding physical conditions of the Arctic, the remote location, and the uncertainty regarding the transportation time increase the challenges related to the transportation of the spare parts in the region. Thus, in the Arctic, in order to maintain the performance goals of production facilities and systems throughout the whole year, it is essential to consider, analyse and model the effect of the dynamic operational condition of the region.

In this paper the concept of a dynamic spare parts transportation model/block diagram (DSTBD) for possible transportation modes and routes has been introduced. The proposed DSTBD approach helps the user to investigate the appropriate path for spare parts transportation, based on user preferences and needs and by considering the time-dependent and time-independent covariates. By employing the proposed approach, the transport modes will be allocated based on the covariates and utilised efficiently. This allows the users to effectively manage their resources. Moreover, by considering time-independent and time-dependent covariates, estimation of spare parts deliverability will reduce the extended downtime and stock-outs due to un-deliverability of spare parts within the scheduled delivery time.

The illustrative case study demonstrates that the operating environment of the Arctic has a significant effect on spare parts transportation, especially during the winter period. The results show that there is more than $60 \%$ delay during the winter season, due to the Arctic operational conditions, when transporting the spare parts from the south-western part of Norway to northern Norway. That means it is 1.6 times more likely that a delay will be experienced during the winter season than the summer season. However, a lack of time to delivery and weather-related data in the Arctic and sub-Arctic environment was a challenge during the computation of the probabilities and spare parts deliverability. The estimated results presented in the case study may thus need to be further modified as the Arctic offshore industry gains experience and new knowledge. 


\section{Acknowledgments}

The work has been funded by The Research Council of Norway and ENI Norge AS through the EWMA (Environmental Waste Management) project, facilitated at UiT The Arctic University of Norway. The financial support is gratefully acknowledged.

The authors would like to thank all anonymous logistic companies, operating in northern Norway, for providing the data related to transportation time.

\section{References}

Ayele YZ, Barabadi A, Markeset T (2013) Spare part transportation management in the High North. Proceedings of the International Conference on Port and Ocean Engineering under Arctic Conditions, POAC'13.

Barabadi A, Barabady J, Markeset T (2011) Maintainability analysis considering timedependent and time-independent covariates. Reliability Engineering \& System Safety 96:210217.

Barabadi A, Barabady J, Markeset T (2014) Application of reliability models with covariates in spare part prediction and optimization-A case study. Reliability Engineering \& System Safety 123: 1-7.

Barabadi A, Ghodrati B, Barabady J, Markeset T (2012) Reliability and spare parts estimation taking into consideration the operational environment - A case study. 2012 IEEE International Conference on Industrial Engineering and Engineering Management (IEEM). 1924 - 1929. doi: 10.1109/IEEM.2012.6838081

Barabadi A, Markeset T (2011) Reliability and maintainability performance under Arctic conditions. International Journal of System Assurance Engineering and Management 2: 205217.

Bekhor S, Ben-Akiva M, Scott Ramming M (2002) Adaptation of logit kernel to route choice situation. Transportation Research Record: Journal of the Transportation Research Board, 7885.

Ben-Akiva ME, Lerman SR, (1985) Discrete choice analysis: theory and application to travel demand, MIT press. Cambridge, USA.

Cox DR (1972) Regression models and life-tables. Journal of the Royal Statistical Society. Series B (Methodological), 187-220.

Distefano S, Puliafito A (2009) Reliability and availability analysis of dependent-dynamic systems with DRBDs. Reliability Engineering \& System Safety 94: 1381-1393.

Gao X, Barabady J, Markeset T (2010) An approach for prediction of petroleum production facility performance considering Arctic influence factors. Reliability Engineering \& System Safety 95: 837-846. 
Ghodrati B, Akersten PA, Kumar U (2007) Spare parts estimation and risk assessment conducted at Choghart Iron Ore Mine: A case study. Journal of Quality in Maintenance Engineering 13: 353-363.

Ghodrati B, Kumar U (2005) Operating environment-based spare parts forecasting and logistics: a case study. International Journal of Logistics: Research and Applications 8: 95-105. Guo X, Liu HX (2011) Day-to-day dynamic model in discrete-continuum transportation networks. Transportation Research Record: Journal of the Transportation Research Board 2263: 66-72.

Haghani A, Jung S (2005) A dynamic vehicle routing problem with time-dependent travel times. Computers \& operations research 32:2959-2986.

Hassan J, Khan F, Hasan M (2012) A risk-based approach to manage non-repairable spare parts inventory. Journal of Quality in Maintenance Engineering 18: 344-362.

Huiskonen J (2001) Maintenance spare parts logistics: special characteristics and strategic choices. International Journal of Production Economics 71: 125-133.

Jacobsen SR, Gudmestad OT (2012) Evacuation from petroleum facilities operating in the Barents Sea. ASME 2012 31st International Conference on Ocean, Offshore and Arctic Engineering. American Society of Mechanical Engineers. 457-466.

Kaufman DE, Smith RL (1993) Fastest paths in time-dependent networks for intelligent vehicle-highway systems application. Journal of Intelligent Transportation Systems 1; 1-11.

Kayrbekova D, Barabadi A, Markeset T (2011) Maintenance cost evaluation of a system to be used in Arctic conditions: a case study. Journal of Quality in Maintenance Engineering 17; 320336.

Khan OA (2007) Modelling passenger mode choice behaviour using computer aided stated preference data.PhD Thesis, Queensland University of Technology.

Li Y, Tan Z, Chen Q (2012) Dynamics of a transportation network model with homogeneous and heterogeneous users. Discrete Dynamics in Nature and Society, 2012.

Lo HK, Szeto WY (2009) Time-dependent transport network design under cost-recovery. Transportation Research Part B: Methodological 43; 142-158.

Markeset T (2008) Design for high performance assurance for offshore production facilities in remote harsh and sensitive environments. OPSEARCH 45; 275 -290.

Neff JM, Rabalais NN, Boesch DF (1987) Long-term environmental effects of offshore oil and gas development. Taylor \& Francis, Oxon, UK.

ReliaSoft (2007) User's Guide Blocksim 7. ReliaSoft Corporation, USA.

Schaanning MT, Trannum HC, Øxnevad S, Carroll J, Bakke T (2008) Effects of drill cuttings on biogeochemical fluxes and macrobenthos of marine sediments. Journal of Experimental Marine Biology and Ecology 361; 49-57.

Vovsha P (1997) Application of cross-nested logit model to mode choice in Tel Aviv, Israel, metropolitan area. Transportation Research Record: Journal of the Transportation Research Board, 6-15. doi: 10.3141/1607-02

Yerra BM, Levinson DM (2005) The emergence of hierarchy in transportation networks. The Annals of Regional Science 39; 541-553. 


\section{Appendix}

Estimation of the probabilities - $P_{i t}$ - for summer season, for transporting the spare parts from Dusavika to Veidnes via Honningsvåg.

Example - The result from Weibull ++7 analysis shows that for air-cargo and ship-cargo the best-fit distribution is $3 \mathrm{P}-$ Weibull and for truck-cargo, it is Log-logistic. Then, to estimate the probability of using air-cargo $\left(P_{A C}\right)$ from ship-cargo and truck-cargo, Equation (6) can be rewritten as follows:

$$
P_{A C}=\frac{\left(1-\exp ^{-}\left(\frac{t-\gamma}{\eta}\right)^{\beta}\right)}{1+\left[\left(\frac{\exp \left(\frac{(\ln (t)-\mu}{\sigma}\right)}{1+\exp \left(\frac{(\ln (t)-\mu}{\sigma}\right)}\right)+\left(1-\exp ^{-}\left(\frac{t-\gamma}{\eta}\right)^{\beta}\right)\right]}
$$

By substituting the parameters from Table 5 into the Equation (A1), and since, according to the assumption, $t$ equals the scheduled delivery time 1 [ $\left.T_{S D T 1}\right]$, which is 95 hours, then $P_{A C}$ can be calculated as:

$$
P_{A C}=\frac{\left(1-\exp ^{-}\left(\frac{95-10.71}{2.07}\right)^{1.42}\right)}{1+\left[\left(\frac{\exp \left(\frac{(\ln (95)-3.79}{0.04}\right)}{1+\exp \left(\frac{(\ln (95)-3.79}{0.04}\right)}\right)+\left(1-\exp ^{-}\left(\frac{95-94.15}{2.57}\right)^{2.00}\right)\right]}=0.48
$$

Subsequently, the probability of choosing ship-cargo $\left(P_{S C}\right)$ can be calculated as:

$$
P_{S C}=\frac{\left(1-\exp ^{-}\left(\frac{95-94.15}{2.57}\right)^{2.00}\right)}{1+\left[\left(\frac{\exp \left(\frac{(\ln (95)-3.79}{0.04}\right)}{1+\exp \left(\frac{(\ln (95)-3.79}{0.04}\right)}\right)+\left(1-\exp ^{-}\left(\frac{95-10.71}{2.07}\right)^{1.42}\right)\right]}=0.04
$$

In the same approach, the probability of choosing truck-cargo $\left(P_{T C}\right)$ can be calculated as:

$$
P_{T C}=\frac{\left(\frac{\exp \left(\frac{(\ln (95)-3.79}{0.04}\right)}{1+\exp \left(\frac{(\ln (95)-3.79}{0.04}\right)}\right)}{1+\left[\left(1-\exp ^{-}\left(\frac{95-94.15}{2.57}\right)^{2.00}\right)+\left(1-\exp ^{-}\left(\frac{95-10.71}{2.07}\right)^{1.42}\right)\right]}=0.48
$$


Afterwards, the basic principle of probabilities, which states that the summation of all of the probability has to be one, $\sum_{i=0}^{N} P_{i t}=1$, needs to be verified, and Equation (A5) verifies that the calculated probabilities are summed to be 1 .

$\sum_{n=1}^{3}\left(P_{A C}+P_{S C}+P_{T C}\right)=\sum(0.48+0.04+0.48)=1$ 